\title{
O Que Eu Sei Hoje: Reflexões sobre a Pedagogia da Teoria da Música ${ }^{1,2}$
}

\section{What I Know Now: Reflections on Music Theory Pedagogy ${ }^{1}$}

\author{
Elizabeth West Marvin \\ Eastman School of Music \\ bmarvin@esm.rochester.edu
}

Resumo: O livro de Ellyn Spragin, What I Know Now: Letters to My Younger Self (2008), é o ponto de partida deste ensaio, no qual a autora reflete sobre suas experiências pessoais durante trinta anos de ensino de Teoria da Música. Durante aproximadamente vinte desses anos, ela ministrou um curso de pedagogia da teoria da música-campo fértil para o seu próprio aprendizado, enquanto observava jovens professores aprimorarem seu ofício. O ensaio apresenta alguns conceitos importantes desse curso e demonstra como as técnicas de ensino aprendidas via tentativa-e-erro, experimentos, ea observação de seus alunos e colegas têm uma abundante literatura pedagógica e cognitiva que as respaldam. Ela conclui com uma carta escrita para si mesma, quando jovem.

Palav ras-chave: pedagogia, motivação in trínseca, musicalização abrangente, aprendizagem ativa, sala de aula invertida, aprendizagem en volvida na comunidade.

Abstract: Ellyn Spragin's 2008 book, What I Know Now: Letters to My Younger Self, provides a starting point for this essay that reflects on the author's personal experiences in thirty years of music theory teaching. For roughly twenty of those years, she has taught a music theory pedagogy course-a fertile field for her own learning as she has observed young teachers hone their craft. The essay presents some important concepts from that course, and demonstrates how the teaching techniques she learned through trial-and-error, experimentation, and observation of her students and colleagues has a rich body of pedagogical and cognitive research to support it. She concludes with a letter to her younger self.

Key words: pedagogy, intrinsic motivation, comprehensive musicianship, active learning, flipped classroom, community-engaged learning.

\footnotetext{
${ }^{1}$ Uma versão preliminar deste artigo foi apresentada no encontro anual da Music Theory Midwest [regional da Society for Music Theory], em 7 de maio de 2016, na Universidade de Arkansas.

2 Tradução de Ilza Nogueira.
} 


\section{Introdução}

O livro de Ellyn Spragins, What I Know Now: Letters to My Younger Self (2008), toma como ponto de partida um conjunto de entrevistas que a autora realizou com quarenta e uma mulheres bem-sucedidas no comércio, na política, na mídia jornalística e nas artes. Entre as entrevistadas estão Beverly Sills e Vanna White, Madeline Albright e Heather Mills McCartney. A cada uma delas a autora perguntou: "Se você pudesse, de alguma forma, enviar uma carta à jovem que você foi um dia, qual a idade que você escolheria e o que diria essa carta?" (Spragins 2008, p. x). Cada uma das entrevistadas de Spragins escolheu um momento específico da sua vida para dirigir a sua carta-Maya Angelou estava deixando a casa da sua infância pela primeira vez, Ann Curry estava começando um emprego numa equipe de jornalistas dominada por homens, Cokie Roberts era uma jovem mãe equilibrando questões de trabalho e de vida pessoal, e assim por diante. Baseando-me nessa premissa, eu imaginei a carta que eu escreveria a mim mesma aconselhando a jovem Betsy sobre a pedagogia da teoria da música. O desafio de escrever essa carta despertou profundos pensamentos em mim: sobre a natureza do ensino, a pesquisa sobre o ensino, a pedagogia na preparação de novos professores-muito mais do que caberia numa única carta. Então, decidi apresentar em primeiro lugar algumas reflexões sobre o ensino, e encerrar com uma pequena carta auto destinada, onde resumo esses pontos como um conselho para uma jovem professora.

Minhas reflexões começam aqui: com uma história que eu conto todo ano à minha classe de Pedagogia da Teoria da Música sobre um momento de transformação em meu próprio modo de ensinar. Aconteceu quando eu era uma estudante de doutorado, novata na docência e ansiosa para melhorar. Um professor de educação musical, Roy Ernst, foi designado para me observar em um curso de pedagogia no qual eu havia me matriculado. O tópico desse curso era análise atonal da música de Anton Webern. Junto com meus alunos, fizemos círculos ao redor de notas, praticamos a descoberta de formas primárias e etiquetamos os círculos com denominações de classes de conjuntos, resultando em partituras anotadas como a do Exemplo 1.

Embora eu tivesse a impressão de que tinha me saído bem, estava ansiosa pela apreciação e por aconselhamento. Professor Ernst começou pelas observações positivas: minha atitude entusiasmada, a interação com os alunos, o contato de olhos, a clareza da exposição, etc. Ele notou que eu realmente parecia ter gostado de ensinar esse material, e então mudou para algumas perguntas desafiadoras: "O que faz os alunos quererem aprender sobre essa composição? Por que eles devem se dedicar a analisá-la?" Eu fiquei com a língua um tanto presa e não consegui responder apropriadamente. "Estamos aprendendo isso 
porque é o próximo tópico do currículo" não parecia ser um tipo de resposta adequada para a pergunta.

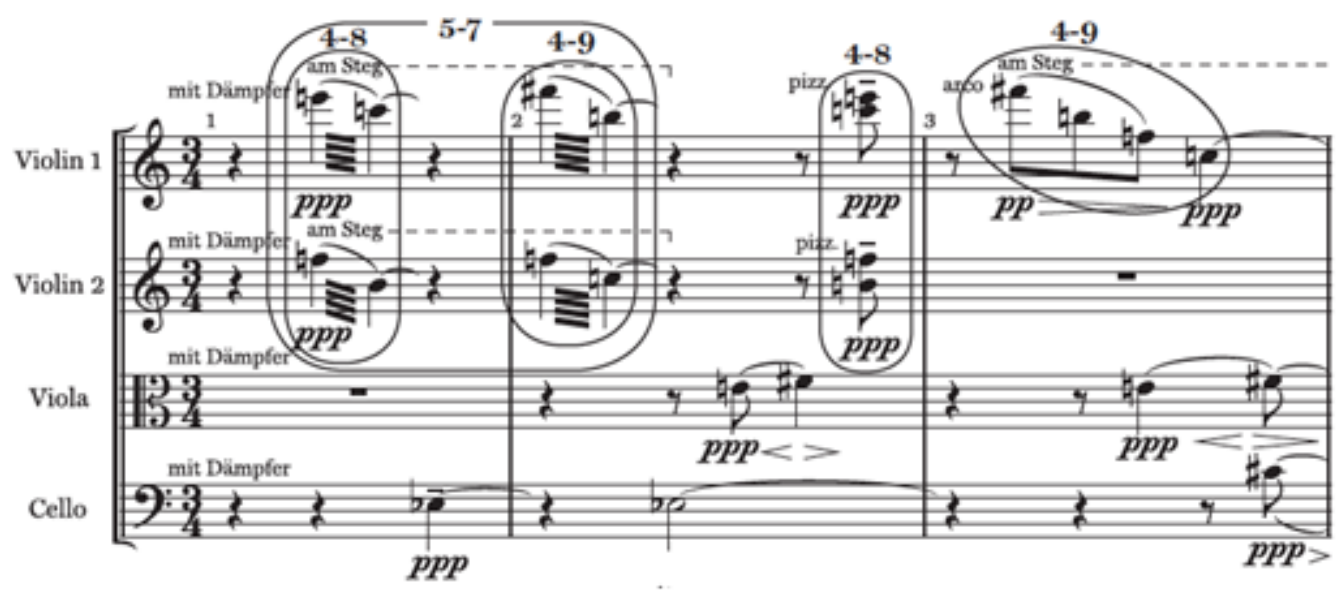

Exemplo 1: Anton Webern, Quarteto de Cordas Op. 5, mov. IV, comp. 1-4

Ele então me apresentou um desafio: na próxima aula, eu deveria fazer os estudantes ouvirem uma peça sem a partitura. Tive dificuldades em compreender o que eu poderia alcançar com isso, se não apontasse aos alunos aspectos estruturais na notação. Preocupei-me: mas se o exercício tomasse o tempo necessário à cobertura dos tópicos analíticos importantes?

No entanto, tentei. Comecei a próxima aula com o 3. movimento do Quarteto de Cordas Op. 4 de Webern. Coloquei o áudio sem haver distribuído partituras, e pedi aos alunos para observarem algumas características que discutiríamos: Qual era a forma? Como a forma se articulava na ausência da tonalidade? O que unia as seções? Que características musicais assinalavam mudanças nas seções? Que tipo de efeito emocional o movimento provocou neles? Depois de ouvirmos, ocorreu uma conversação profunda e entusiasmada, uma discussão de um nível que nunca houve naquela classe. Os alunos estavam envolvidos e ansiosos para falar sobre suas experiências de escuta, e minha abordagem pedagógica mudou para sempre.

Essa história motiva várias ideias, às quais eu recorro repetidamente no meu curso de pedagogia. Compartilho aqui seis delas, organizadas em torno de dois temas guias: foco na música e na musicalidade, e planejamento de cada aula visando o envolvimento dos alunos.

\section{Foco na música e na musicalidade}

Proposta 1. Maximize a motivação intrínseca. O que motiva nossos alunos a se matricularem em um curso de teoria da música? Sentados diante de 
nós estão jovens que devotaram anos à performance musical, que estão engajados numa habilitação principal ou secundária em Música, que ensaiam individualmente e em conjunto durante horas, diariamente. Sua paixão por música os trazem à sala de aula, e nossos modos de ensino algumas vezes falham em tirar partido desse fato. Nosso trabalho é aproveitar a motivação intrínseca pela música e transferir esse entusiasmo para a teoria da música. A pesquisa sobre motivação dá uma visão sobre como isso pode ser feito.

Ryan e Deci (2000, p. 56) definem motivação intrínseca como o envolvimento numa atividade "antes pelas satisfações que lhe são inerentes do que por alguma outra consequência identificável". Uma das primeiras demonstrações desse princípio foi um estudo no qual Deci pediu a participantes, que trabalhavam individualmente num laboratório, a montagem de um cubo soma ${ }^{3}$ em formas especificadas (Deci 1971). No meio do experimento, o pesquisador anunciou que o tempo para a montagem das primeiras formas se esgotara e que ele sairia do laboratório por alguns instantes, retornando logo com mais instruções. Enquanto esteve ausente, o pesquisador observou como os participantes usaram o tempo livre-ou montando outras formas por pura diversão ou abandonando o quebra-cabeças para ler revistas que deixara próximas. A motivação intrínseca foi medida pelo número de segundos que eles continuaram a montar o quebra-cabeças. Crucial ao projeto era a comparação de um grupo de controle que não recebeu recompensas externas, com um grupo experimental recompensado com dinheiro para cada formato corretamente montado após a segunda de três tentativas. Enquanto a recompensa monetária aumentava a motivação na segunda tentativa, quando as recompensas eram retiradas na terceira vez, a motivação desabava. Comparativamente, o grupo de controle não recompensado mostrou uma motivação crescente da primeira à terceira tentativa-eles completaram os quebra-cabeças pelo prazer intrínseco da tarefa, não pela recompensa extrínseca.

Ryan e Deci sugerem que a motivação intrínseca se fundamenta em três necessidades humanas básicas: competência, autonomia e afinidade-isto é, o desejo inerente de desenvolver nossas habilidades, de agir de acordo com nós mesmos, e de nos relacionarmos com outros e com nosso ambiente. Como professores, sabemos que nem todas as tarefas ou tópicos são intrinsecamente motivadoras a muitos dos nossos alunos. Nessas situações, Ryan e Deci argumentam que motivadores externos podem ajudar, se promoverem competência, autonomia e/ou afinidades. Em suas próprias palavras:

\footnotetext{
${ }^{3}$ O cubo soma é um quebra-cabeça criado pelo poeta e matemático dinamarquês Piet Hein. O objetivoé usar os sete policubos, peças formadas por pequenos cubos unitários, para montar um cubo de $3 \times 3 \times 3$ unidades.
} 
alunos podem realizar ações extrinsicamente motivadas com desgosto, relutância e desinteresse, ou, por outro lado, com uma atitude de disposição que reflete um aceitação íntima do valor ou da utilidade da tarefa... Saber como promover formas de motivação extrínseca mais ativas e volitivas (versus passivas e controladas) torna-se uma estratégia essencial para o sucesso do ensino (Ryan e Deci 2000, p. 55).

Quando nos sentimos competentes numa tarefa, sentimo-nos bem desempenhando-a. Para reforçar a competência, professores devem planejar uma série de tarefas progressivamente desafiadoras mas realizáveis, proporcionando treinamento apropriado, reação positiva e recompensas verbais. Para reforçar a autonomia, devem conceber atividades que sejam "ativas e volitivas" em vez de "passivas e controladas". Finalmente, os estudantes apreciam a sensação de afinidade quando se sentem parte de uma comunidade de aprendizagem que lhes dá suporte. Professores podem facilitar o senso de comunidade tratando os alunos como indivíduos e a classe como um grupo, num ambiente de cuidado.

Mostramos aos alunos que nos importamos com eles através da proximidade física, do contato de olhos e de expressões faciais; respeitando-os como indivíduos, conhecendo seus nomes e antecedentes, proporcionando oportunidades para que cada um fale e pergunte num ambiente sem críticas e sem favoritismo, dando acompanhamento quando perderem uma aula, e por meio de várias pequenas gentilezas tanto em classe quanto avaliando tarefas. Nós facilitamos a afinidade, quando a classe sente que há um objetivo compartilhado.

Quando motivadores extrínsecos são concebidos com esses elementos em mente - competência, autonomia e afinidade -, o aluno passa a valorizar a atividade (teoria da música) como parte de um objetivo intrinsecamente motivado: fazer a vida e a carreira com a música.

Proposta 2. Favoreça o ensino contextual sobre o não-contextual (tomando-se como contexto, música): Imagine uma aula sobre introdução a intervalos, em que os alunos vejam somente a notação, como no Exemplo 2a, e tenham tarefas somente como em $2 b$. Não é de admirar que o/a estudante perceba alguma desconexão entre a teoria da música e a música de que gosta.

O ensino não-contextual introduz conceitos via exemplos simplificados que são abstratos, geralmente em semibreves, numa única pauta, como vemos no Exemplo 2a. Conceitos são tipicamente ensinados como listas de regras para serem decoradas, e as aulas enfatizam exercícios de treinamento, focados em notação e escrita. Exemplos auditivos ou estão completamente ausentes ou são não-contextuais (como ouvir tríades ou intervalos isoladamente); poucos, ou mesmo nenhum dos exemplos são tirados de peças de música. O ensino contextual, ao contrário, inicia com o repertório musical (através de audição e de 
partituras) e extrai as ideias teóricas do contexto musical, via um processo de "aprendizagem pela descoberta".

Exemplo 2: Uma introdução não-contextual aos intervalos:

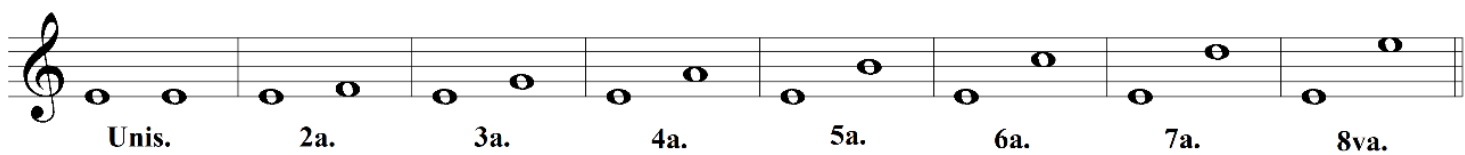

2a. Esquema do professor no quadro-negro

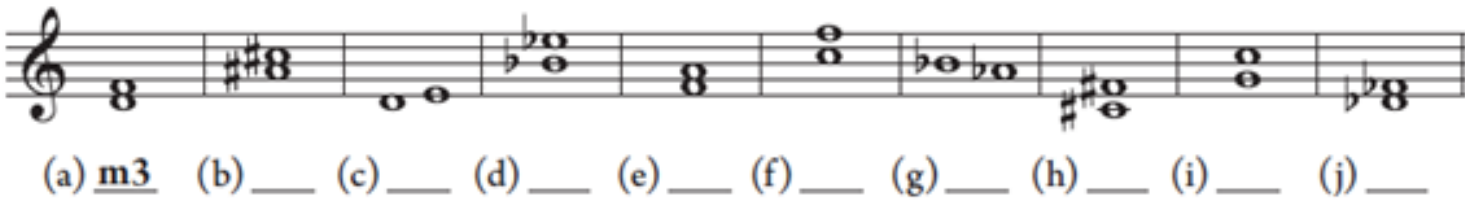

2b. Dever de casa

Uma introdução a intervalos poderia começar fazendo os alunos ouvirem a música do Exemplo 3. O professor poderia falar um pouco sobre a infância de Mozart como um menino prodígio itinerante e seus improvisos em forma de variações sobre melodias folclóricas comuns, como essa.
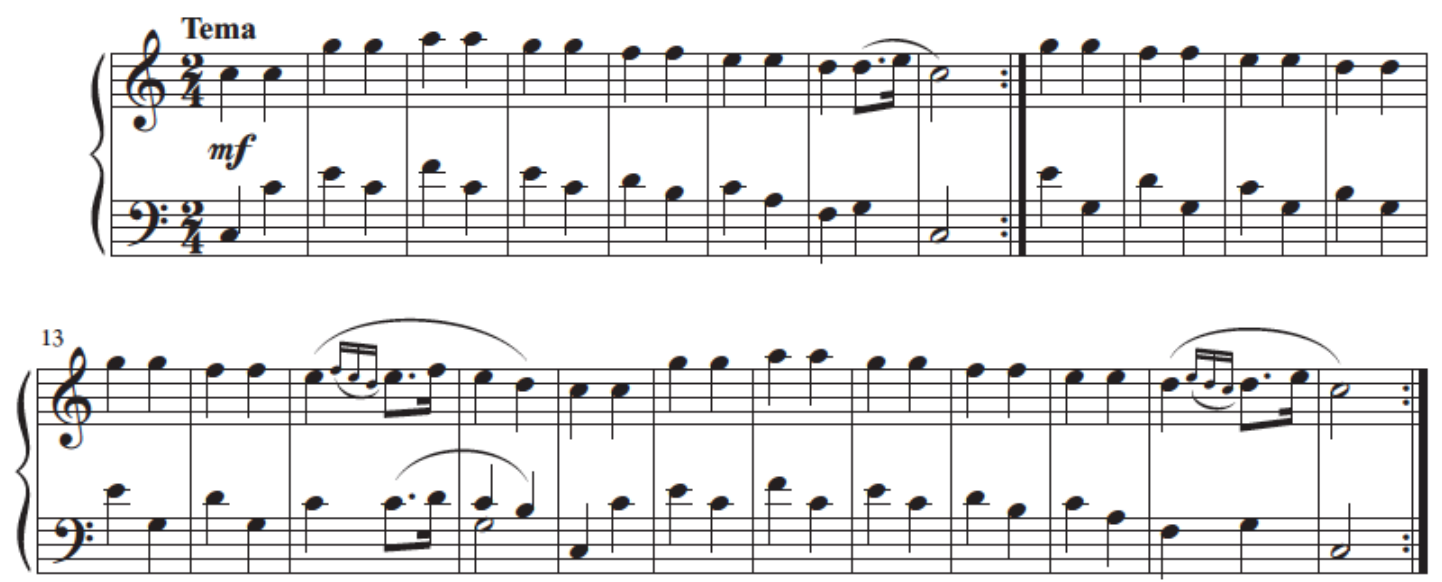

Exemplo 3 - Uma introdução contextual dos intervalos:

Mozart, Variações sobre Ah, vous dirai-je, Maman, c. 1-24

Após ouvir o tema e algumas poucas variações, os alunos poderiam discutir sobre o que faz esse início simples soar diferente do que vem depois. Em seguida, o professor poderia perguntar: Para escrever uma configuração a duas vozes como essa, como um compositor saberia quais notas caem bem com a melodia dada? Isso poderia conduzir à introdução aos intervalos-uma forma de medir distâncias entre notas e de classificar quais distâncias soam agradáveis e estáveis (consonâncias) e quais soam mais turbulentas ou instáveis 
(dissonâncias). Os alunos poderiam trabalhar em duplas, contando os intervalos harmônicos do exemplo de Mozart, com os nomes das notas, ignorando oitavas por enquanto, para chegar aos números dos intervalos: Dó a Dó é 1, Mi a Sol é 3, Dó a Sol é 5, e assim por diante. Poderiam se exercitar em quais intervalos são consonâncias, notando os que ocorrem mais frequentemente (como 3 ou 6), e em quais são dissonâncias, que ocorrem raramente, em contextos específicos. A partir desse ponto, a discussão de intervalos estaria aberta, e os estudantes poderiam compreender a relevância do tópico teórico-musical na realidade da música tocada. "Descobrindo" uma função possível dos intervalos (como definir o fluxo de consonâncias e dissonâncias numa peça), analisando os intervalos da obra com um parceiro e ouvindo-os em contexto, o estudante provavelmente estará mais apto a compreender, interiorizar e lembrar do conceito do que estaria numa introdução não-contextual.

Praticamente qualquer tópico pode ser introduzido através do repertório musical e por meio do aprendizado pela descoberta. Shaffer e Hughes (2013) descrevem uma aula muito parecida com as minhas, onde estudantes descobrem por si mesmos os princípios do contraponto de espécies comparando sucessivos exemplos musicais de Salzer e Schachter (1969) e trabalhando colaborativamen te em equipes. Em minhas aulas, equipes desenvolvem uma lista progressiva de regras de contraponto; nas aulas de Shaffer eles tuitam o que descobrem. Até agora, quando eu desenvolvo um novo curso ou inicio um novo tópico, desafiome a começar cada aula com uma peça musical. ${ }^{4}$ Uma abordagem direcionada ao repertório combinada com a aprendizagem pela descoberta envolve os níveis superiores da taxonomia revisada de Bloom para o aprendizado (Krathwohl 2002, p. 214) - lembrar, compreender, aplicar, analisar, avaliar, criar - e conduz naturalmente à composição de estilos como uma atividade criativa culminante (o mais alto nível da taxonomia de Bloom).

O ensino baseado em repertório tem diversos benefícios pedagógicos: (1) proporciona ao estudante uma evidência concreta da relevância da teoria da música para a música que os inspira, (2) reforça cognitivamente novos tópicos por meio do aprendizado ativo e (3) prepara o aluno para suas próprias explorações futuras da estrutura musical em novas peças, fornecendo um modelo de procedimento.

Proposta 3. Ensine com uma mentalidade de "PMC". Nos anos 1960s-70s, o Projeto Música Contemporânea ou PMC (Contemporary Music Project-CMP), financiado pela Fundação Ford, explorou inovações na pedagogia da música desde o ensino fundamental ao nível universitário. Originalmente liderado por pedagogos compositores, objetivava levar a música contemporânea aos

\footnotetext{
${ }^{4}$ Ver também Clendinning e Marvin (2016), onde cada capítulo é iniciado com peças musicais.
} 
currículos escolares. Quando o movimento se desenvolveu, abraçou a música de todos os períodos históricos - música ocidental e não-ocidental, erudita e popular - e tornou-se conhecido como "Musicalização Abrangente" (Thomson 1990, Truland 1999). No nível universitário, a musicalização abrangente objetivava derrubar os muros entre teoria da música, história da música, composição e performance. Entre as universidades líderes do movimento estavam Northwestern University, Indiana University, University of Southern California e San Diego State; aulas experimentais e simpósios foram realizados na Florida State University e na Eastman School of Music (Thompson 1990, p. 23 e Truland 1999, p. 3-4).

Os currículos da musicalização abrangente normalmente prosseguiam da música medieval à contemporânea, com estudantes analisando, teorizando, compondo e tocando, todos na mesma classe. Um tópico fundamental como "notação musical" poderia apresentar os estudantes aos neumas medievais e à notação mensurada juntamente com a notação normal na pauta e a notação gráfica contemporânea. Exemplos de canto gregoriano, Guillaume Dufay, J. S. Bach e Krzysztof Penderecki poderiam aparecer lado a lado. Livros-texto e antologias publicadas nessa época são exemplos fascinantes dessa abordagem (Cogan e Escot 1976, Cooper 1981, Ward-Steinman 1976, Wittlich e Humphries 1974). Estudantes eram expostos a amplas faixas do repertório musical, podendo compor organum e fauxbourdon tanto quanto corais a quatro vozes e peças dodecafônicas, e tocar tudo isso em classe.

Sem dúvida, os alunos tinham muito o que ganhar com essa abordagem: com sua ênfase na integração das disciplinas musicais, sua relevância para a performance musical e a composição, e sua continuidade histórica. No entanto, a musicalização abrangente perdeu seu prestígio e praticamente desapareceu dos livros-texto modernos e da pedagogia. Apesar de todas as suas qualidades, essa pedagogia sofreu com o problema de ter mais abrangência do que profundida de, produzindo alunos que sabiam alguma coisa sobre muito tópicos, mas eram incapazes de alcançar um verdadeiro domínio deles. Para obter sucesso a abordagem requeria alunos auto-motivados, professores virtuosi (ou equipes de professores) e classes de pequeno tamanho, e isso criou vários problemas quando os alunos se transferiam de uma instituição para outra.

Apesar desse resultado insatisfatório, o movimento PMC deixou lições importantes aos professores de hoje. Ele nos faz lembrar que peças musicais não existem no vácuo (e nem existem como o exemplo "perfeito" de um acorde de sexta aumentada). Professores com mentalidade PMC, quando apresentam uma nova obra, fazem-no com algumas palavras sobre sua história composicional ou sobre a função do seu gênero na época (desde partes da Missa a um recital de Lieder; de uma canção Tin Pan Alley à musica aleatória). Esses professores lerão a poesia de uma canção antes de ouvi-la, discutirão seu significado e esquema de 
rimas. Eles pedirão aos estudantes para improvisar e compor, dando suporte em sala de aula e executando suas realizações. O espírito da musicalização abrangente pode subsistir, mesmo num currículo estruturado mais tradicionalmente, se conservarmos seus princípios louváveis em nossas mentes e em nossos corações.

\section{Programas Centrados no Envolvimento do Estudante}

Proposta 4. Evite a postura de "detentor do saber". Num ensaio bastante citado de 1993, Alison King contrastou dois estilos de ensino: o do "detentor do saber" - o professor sabe-tudo que pontifica em um pódio à distância - com o do "instrutor companheiro", o facilitador que ajuda os alunos a construir seu próprio conhecimento (King 1993, p. 30). O segundo método (também conhecido como aprendizagem baseada no questionamento, aprendizagem ativa, ou aprendizagem construtivista) encoraja os alunos a serem aprendizes ativos, a interagir com o material em estudo em vez de recebê-lo passivamente. King fornece vários exemplos concretos de estratégias de aprendizagem ativa que podem ser incorporados em qualquer tipo de aula, tais como "compartilhamento de raciocínio entre pares" (pequenas discussões entre parceiros inseridas numa exposição), fazendo com que os alunos desenvolvam fluxogramas ou gráficos, construam críticas de uma obra de arte ou de uma passagem, ou trabalhem em duplas resumindo uma palestra (King 1993, p. 31).

A aprendizagem ativa pode ter lugar naturalmente na aula de teoria da música, se tomarmos alguns minutos para elaborar atividades apropriadas e variadas. Afortunadamente, há vários recursos dos quais podemos extrair ideias. Shaffer e Hughes (2013) descrevem abordagens como a da sala de aula invertida para teoria da música; nela, o modelo de exposição em sala de aula e de dever de casa é invertido e os estudantes passam o tempo da aula com atividades de aprendizagem ativa, enquanto o professor está ali para responder questões e guiar o foco dos alunos. $\mathrm{O}$ artigo de Folio e Kreinberg, inteligentem ente denominado "Blackboard and Wikis and Blogs, Oh My" (2010), descreve vários projetos de aprendizagem colaborativa que os estudantes começam em sala de aula e depois desenvolvem, assincronicamente, fora da classe, via wikis ou blogs. Os alunos desenvolvem conjuntamente um texto em que respondem a questões sobre uma leitura ou uma peça musical. O formato colaborativo proporciona responsabilidade ao trabalho dos estudantes, pois eles sabem que suas contribuições serão lidas e revisadas por outros no seu grupo e a nota final será compartilhada. Os autores recomendam que os alunos assumam um entre cinco papeis em seu grupo - líder, redator, especialista em multimeios, verificador de dados, ou revisor - para se assegurar de que todos estejam participando e desempenhando uma função distinta (Folio e Kreinberg 2010, p. 168-169). 
Zbikowski e Long (1994) descrevem várias atividades de aprendizagem cooperativa, cada uma delas com dois objetivos complementares: “primeiramente, os alunos devem aprender e entender o material distribuído, e depois eles devem se assegurar de que todos os membros do grupo compreendam e aprendam o material" (1994, p. 138). Os autores apresentam quarto exemplos de atividades de aprendizado ativo, uma das quais tem interesse especial para mim: a percepção da fundamental, ou mais precisamente o solfejo dos acordes. Esse tipo de treinamento prático é uma atividade clássica em aulas de teoria musical: tipicamente dá-se aos alunos vários acordes para grafarem, individualmente, em silêncio, em suas carteiras; depois, alguns estudantes levantam as mãos e vêm ao quadro escrever, ou leem em voz alta suas soluções, enquanto o professor escreve no quadro. $O$ professor controla a atividade (mais do que controla os estudantes), e alguns alunos podem se distrair sem serem notados. No ambiente do aprendizado cooperativo descrito por Zbikowski e Long (1994, p. 146-148), os alunos são distribuídos em pares e cada par recebe dois pedaços de papel com conjuntos de acordes para serem grafados (por exemplo, "como é o acorde V6/5 da mediante em Fá\# menor?"), e ainda as respostas corretas. Neste caso os alunos se tornam responsáveis pelo seu aprendizado: o aluno 1 lê o nome de um acorde para o aluno 2, confere a resposta no papel e ajuda o colega até que ele acerte; em seguida eles trocam de função e continuam o procedimento até que tenham decifrado todos os acordes dados nos dois papéis. Nessa sala de aula, há um zumbido de atividade; os alunos se ajudam mutuamente no aprendizado, procuram estratégias para explicar a montagem dos acordes uns aos outros, e todos se envolvem. Os autores sugerem concluir com um pequeno teste para a atribuição de notas individuais. A estratégia aumenta a exigência e incentiva os alunos a trabalharem mais para entender o tópico antes do teste.

Proposta 5. Crie um ambiente natural de aprendizagem crítica. O livro de Ken Bain, What the Best College Teachers Do (O Que fazem os melhores professors universitários), encoraja professores a criarem um ambiente natural de aprendizagem crítica para seus alunos: natural, porque as competências a serem aprendidas estão incluídas em tarefas autênticas que eles julgam interessantes; e crítica, porque ensina os alunos a pensar criticamente, a fazer perguntas importantes, e a raciocinar a partir da evidência apresentada (Bain 2004, p. 99). Embora isso sugira uma aprendizagem baseada em projetos, Bain argumenta que até mesmo uma palestra poderá criar um ambiente desse tipo, se incluir cinco elementos: coloque um problema ou um questionamento intrigante, conduza os estudantes a compreender sua importância, engaje os alunos em raciocínios de ordem superior, ajude-os a responder a questão e proponha a eles uma próxima questão (Bain 2004, p. 100-103). 
Podemos considerar um projeto de composição de emulação de um estilo como um ambiente de aprendizagem crítica natural para uma aula de teoria da música. A questão é: “Como posso eu escrever um minueto tão próximo ao estilo de Mozart que poderia enganar alguém?" A relevância dessa questão gera muitas outras. Como os minuetos eram compostos na época de Mozart? Que terminologias e métodos Mozart usou para aprender o estilo? Em que tipos de composições aparecem minuetos? Como os princípios da escrita para SATB que aprendemos neste semestre podem se adaptar a essa textura e estilo? Como os tópicos de harmonia que aprendemos (dominantes secundárias, modulação, sequência, forma binária) podem aparecer em um minueto estilisticamente adequado? Os alunos se engajam em raciocínios de ordem superior comparando minuetos de Mozart e Haydn, contrastando movimentos diferentes, analisando suas semelhanças e sintetizando essas informações em suas próprias composições.

Bain incita os professores a auxiliarem os alunos a responder as questões, e aí entra em cena a ideia de "andaime", no sentido de "suporte". Andaime é um "recurso de planejamento" de uma atividade ou curso e, ao mesmo tempo, um "processo de interação" entre aluno e professor (Van Lier 2007, 59), onde uma gradação de ações pedagógicas num ambiente de apoio conduz a uma eventual transferência, pela qual o estudante - então já adequadamente preparado pode assumir seu próprio aprendizado. Assim nós não dizemos simplesmente aos alunos que sua tarefa é escrever um minueto no estilo de Mozart. Em vez disso, provemos um andaime, na forma de atividades que preparem e apoiem os alunos enquanto eles completam sua composição. Em qualquer ponto no processo, o professor pode diagnosticar problemas (por exemplo, se um estudante não compreende como modular com um acorde pivô) e remediar. Quando o aluno se aproxima do final do projeto, o andaime é removido.

No segundo semestre do meu curso para os primeiranistas na universidade, os alunos escrevem um minueto para quarteto de cordas. Além de ouvir e analisar muitos minuetos clássicos para teclado e quarteto de cordas, eles completam uma série de tarefas progressivas que funcionam como andaime: 1) escrever um período contrastante modulante com acompanhamento de teclado; 2) esquematizar a forma do minueto proposto, com as tonalidades, e decidir-se qual das estratégias composicionais de Riepel (Monte, Ponte ou Fonte) utilizar na segunda metade ; 3) escrever uma versão para teclado de todo o minueto, analisando-a com números romanos e rotulando a forma; 4) "orquestrar" o início para quarteto de cordas utilizando um programa de notação musical; e 5) trazer

\footnotetext{
${ }^{5}$ Um recurso maravilhoso para se ensinar composição de minueto da época clássica é o artigo de Stefan Eckert "So, you want to write a Minuet?" [Eckert 2005]. Ele fornece trechos do tratado pedagógico oitocentista de Riepel, ideias para a aula, repertório para análise e uma passagem defeituosa de um "aluno" de Riepel para a turma criticar.
} 
a redução de piano para uma aula individual de 10 minutos com o professor, que lhe dará opiniões sobre harmonia, forma, estilo, textura, etc., com sugestões para revisões. Finalmente, os alunos completam a composição sozinhos e ouvem uma execução durante a aula; vota-se nos melhores, que são premiados e executados em um concerto.

Muitos dos exemplos de ambientes de aprendizado crítico natural de Bain incluem um elemento do "mundo real"; por exemplo, um professor cujos alunos estavam completando um estudo etnográfico de comunidades mexicanas e angloamericanas numa cidade fronteiriça do Texas conseguiu que os ensaios de seus alunos fossem publicados por um jornal local (Bain 2004, p. 60-63). Este tipo de atividade aplicada fora da sala de aula, chamado "aprendizagem engajada na comunidade", pode variar desde um concerto público de obras compostas para o curso até a publicação de notas de programa para um concerto local, ou pequenas demonstrações para uma aula aberta sobre a aplicação da análise à performance. Planejar uma execução ou publicação como meta dá ao projeto maior relevância na carreira estudantil e motivação para resultados mais ambiciosos. Recentemente eu assisti uma aula em que o professor levou os alunos para um lar de idosos, onde realizou um concerto com seus minuetos. $\mathrm{O}$ programa para este concerto, intitulado "Isto é Mozart?", misturou composições dos alunos com minuetos autênticos de Mozart. Durante o concerto, os residentes do lar de idosos votaram nas composições que eles julgaram ser de Mozart - e isso, sim, é um ambiente de aprendizagem crítica natural!

Proposta 6. Ensine em diferentes modalidades. Muitos aprendizes sabem, intuitivamente, seu próprio estilo de aprendizagem: visual, auditivo, cinestésico ou social. Proponentes de estilo de aprendizagem creem que professores podem melhorar a aprendizagem do estudante testando e diagnosticando estilos individuais, e então adaptando métodos de ensino a cada estilo preferido do estudante. Contudo, Riener e Willingham (2010) consideram essa teoria um "mito", e notam que nenhum estudo bem projetado e estatisticamente confiável jamais validou essa abordagem. A despeito disso, creio que a atenção aos estilos de aprendizagem pode melhorar o ensino. Não estou advogando que devamos nos adaptar servilmente aos estilos particulares de cada estudante, mas penso que devemos conscientemente variar nossos modos de apresentação-visual, aural, cinestésico e social - a cada aula, a fim de atender as necessidades de cada aprendiz.

Em minhas aulas de pedagogia, eu encorajo professores iniciantes a escrever enquanto falam, cantar o que escrevem (quando escrevem a notação musical-o que um colega chama "ensinar em recitativo"), reunir os alunos em torno do teclado e dar regularmente oportunidades de trabalho em grupo ou em parceria. Escrever enquanto se fala não é tão fácil para alguns jovens professores, 
cuja tendência natural é confiar somente na palavra falada. Contudo, falar enquanto se escreve simultaneamente no quadro uma lista de ações para serem realizadas, ou a definição de um novo termo introduzido recentemente, proporciona ao estudante um modelo do que copiar em suas anotações, e ajuda o processamento dos aprendizes visuais. Essas técnicas podem ser usadas diariamente e, definitivamente, se 10 minutos passam numa aula sem haver música soando, o plano de aula deve ser repensado.

Mesmo após discutir estilos de aprendizagem, é impressionante quantos estudantes de teoria da pedagogia, em sua primeira oportunidade de ensino, irão simplesmente falar ou palestrar para a classe. Em nossa crítica, observamos que para aprendizes visuais aquela definição ou grafia de acorde deveria ter sido escrita no quadro; para aprendizes auditivos, a qualidade do acorde e a resolução deveriam ter sido tocadas ou cantadas; para aprendizes cinestésicos, estudantes deveriam ter trabalhado no piano para sentirem as diferentes espacialidades dos acordes; para aprendizes sociais, um exercício em parceria poderia ter sido planejado. Incorporar algumas dessas ideias romperá a monotonia do discurso professoral, e os estudantes tenderão menos a se desligar e mais a se engajar com o material. Professores que introduzem o tópico com uma abordagem direcionada ao repertório podem recorrer a dois ou a três estilos de aprendizagem, simplesmente escutando a obra, trabalhando em equipes para responder algumas questões sobre sua estrutura, e escrevendo uma lista dos resultados do trabalho em grupo no quadro.

Um último aspecto sobre estilos de aprendizagem tem a ver com a grande quantidade de informação transmitida em cada aula e a habilidade variável dos estudantes de assimilarem todas elas. $\mathrm{O}$ "detentor do saber" quer impressionar os estudantes com quanto ele sabe sobre um tópico, e apresenta a informação principal junto a todas as variantes, as regras junto às exceções. Muito disso pode entrar por um ouvido e sair por outro para alguns estudantes. Ao contrário, planeje uma trajetória de várias aulas para cada novo tópico; por exemplo, intervalos maiores e justos no primeiro dia, adicionando intervalos menores no segundo dia e diminutos/aumentados no terceiro dia. Distribuindo a informação em várias aulas, você poderá alocar tempo para cantar, escrever e tocar, examinar o repertório, praticar a grafia em pequenos grupos, e outras tarefas de aprendizagem ativa.

Uma outra forma de planejar a trajetória de um novo tópico é via "aprendizagem em espiral" 6 . Uma abordagem em espiral apresenta um tópico

\footnotetext{
${ }^{6}$ Nos anos 1960s, Jerome Bruner apresentou a ideia de um currículo em espiral em seu livro The Process of Education (1960, p. 52-54), debatendo sobre uma ampla trajetória para a educação durante toda a vida de um aprendiz, desde criança à idade adulta. $\mathrm{O}$ aprendizado pela descoberta, discutido acima em relação ao ensino baseado em repertório, também pode ser identificado na obra de Bruner (1960, p. 20-22).
} 
amplo no início do curso e retorna a ele várias vezes no semestre ou ano letivo, adicionando camadas de detalhes ou complexidade. Por exemplo, no Exemplo 3 apresentamos a ideia de que dissonâncias são mais raras do que consonâncias, e são tratadas de forma especial. Podemos retornar ao conceito quando estudarmos notas de passagens, retardos, resoluções do acorde de sétima e a condução de vozes na harmonia cromática. Um outro exemplo: os alunos aprendem no primeiro semestre que pré-dominantes preparam as harmonias de dominante; começam com ii e IV, mas espiralam de volta à função de prédominante quando estudam cadências frígias, acordes de $6^{\underline{a}}$ napolitana e acordes de $6^{\mathrm{a}}$ aumentada (Rogers 2004, p. 57). Um projeto em espiral proporciona aos estudantes uma plataforma para ideias novas e um sentido de continuidade durante o semestre ou ano. A aprendizagem em espiral também pode ser utilizada com o repertório, fazendo com que a turma retorne a uma composição de vez em quando para adicionar novas camadas de compreensão. Pensemos novamente no tema de Mozart do Exemplo 3. Quando as variações são adicionadas a esse tema, a composição pode ser utilizada para o ensino de qualquer ou todos os seguintes conceitos que ocorrem em diferentes pontos do currículo: intervalos, cadências, contraponto a duas vozes, notas melódicas, tríades, ponto de pedal, retardos, tonalidade paralela menor, sequências, dominantes secundárias, forma binária e variação seccional. Além disso, cada vez que os alunos revisitam a peça ela se torna mais familiar, como um velho amigo, aumentando seus conhecimentos e o gosto pelo repertório importante e pelos compositores (Clendinning e Marvin 2016, p. xxvi).

Como prometido no princípio do artigo, concluo estas reflexões sobre o ensino com uma carta endereçada a mim mesma, dirigindo-a à então jovem universitária que estava prestes a se tornar professora. 
Querida Betsy,

Você acreditaria se eu te dissesse que, passados todos esses anos, você ainda estará ensinando em Eastman? Lá, você aprenderá muito com seus colegas e alunos. Lembra-se de quando Roy Ernst lhe disse que fizesse a turma ouvir sem a partitura? Você pensou que ele estava louco! Como você poderia cobrir os tópicos necessários sem se referir a uma partitura? Você aprendeu naquele dia que o mais importante não é "cobrir os tópicos", mas assegurar o aprendizado do aluno. Isso é que é ensinar.

Com o tempo, você também aprenderá outras lições importantes. Principalmente, você aprenderá que os alunos se engajam mais quando uma peça musical maravilhosa é o ponto de partida de uma aula. Embora isso agora pareça óbvio, é surpreendente que os professores iniciantes frequentemente queiram focalizar primeiro a teoria e só fornecer uns poucos e relutantes exemplos musicais ao final, para ilustrar o conceito. Em segundo lugar, você descobrirá quão importanteé incorporar tarefas de aprendizagem ativa na aula - como discussão, trabalho de grupo, projetos baseados em repertório e composição de estilos - para minimizar a ênfase em você mesma enquanto transmissora de sabedoria e, ao contrário, tornar-se uma facilitadora da aprendizagem. Finalmente, você se tornará mais consciente das diferenças individuais sobre como seus alunos aprendem; e você perceberá que sua sensitividade aos variados estilos de aprendizagem pode tornar a aula melhor para todos.

Lembre-se sempre de que pessoas diferentes têm dons diferentes. Focalize no que você faz bem. Os alunos também têm talentos diferentes - talvez o que esteja tendo dificuldades com o baixo cifrado possa compor e executar um belo minueto. Abrace o seu interesse pela pedagogia. Ela ganhará credibilidade como campo de pesquisa na área (e você vai até escrever um livro didático!). Lembre-se de que ensinar não é tanto sobre você quanto é sobre os alunos e sobre a música. Relaxe e desfrute ambos!

Do seu futuro eu,

Betsy 


\section{Referências}

1. Bain, Ken. 2004. What the Best College Teachers Do. Cambridge: Harvard University Press.

2. Bruner, Jerome S. 1960. The Process of Education. Cambridge: Harvard University Press.

3. Clendinning, Jane Piper e Marvin, Elizabeth West. 2016. The Musician's Guide to Theory and Analysis, $3^{\text {rd }}$ ed. New York: W. W. Norton.

4. Cogan, Robert e Escot, Pozzi. 1976. Sonic Design: The Nature of Sound and Music. Upper Saddle River: Prentice Hall. [Em português: Cogan, Robert e Escot, Pozzi. 2013. Som e Música: A Natureza das Estruturas Sonoras. (Trad: Gerling, Cristina, Gonçalves Fernando e Muniagurria, Carolina). Porto Alegre: UFRGS Editora.]

5. Cooper, Paul. 1981. Perspectives in Music Theory: An Historical-Analytical Approach. New York: Harper-Collins College Division.

6. Deci, Edward. 1971. Effects of Externally Mediated Rewards on Intrinsic Motivation. Journal of Personality and Social Psychology 18, no. 1, p. 105-115.

7. Eckert, Stefan. 2005. 'So, you want to write a Minuet?' - Historical Perspectives in Teaching Theory. Music Theory Online 11, no. 2.

8. Folio, Cynthia e Kreinberg, Steven. 2009-2010. Blackboard and Wikis and Blogs, Oh My: Collaborative Learning Tools for Enriching Music History and Music Theory Courses. College Music Symposium 49/50, p. 64-175.

9. King, Alison. 1993. From Sage on the Stage to Guide on the Side. College Teaching 41, no. 1, p. 30-35.

10. Krathwohl, David R. 2002. A Revision of Bloom's Taxonomy: An Overview. Theory Into Practice 41, no. 4, p. 212-218.

11. Riener, Cedar e Willingham, Daniel. 2010. The Myth of Learning Styles. Change: The Magazine of Higher Learning 42, no. 5, p. 32-35.

12. Rogers, Michael R. 2004. Teaching Approaches in Music Theory: An Overview of Pedagogical Philosophies. Carbondale: Southern Illinois University Press. 
13. Ryan, Richard M. e Deci, Edward L. 2000. Intrinsic and Extrinsic Motivations: Classic Definitions and New Directions. Contemporary Educational Psychology 25, no. 1, p. 54-67.

14. Salzer, Felix e Schachter, Carl. 1969. Counterpoint in Composition: The Study of Voice Leading. New York: Columbia University Press.

15. Shaffer, Kris e Hughes, Bryn. 2013. Flipping the Classroom: Three Methods. Engaging Students: Essays in Music Pedagogy 1. Accessed April 12, 2016:

http://flipcamp.org/engagingstudents/shafferintro.html

16. Spragins, Ellyn. 2008. What I Know Now: Letters to My Younger Self. New York: Broadway Books.

17. Thomson, William. 1990. The Anatomy of a Flawed Success: Comprehensive Musicianship Revisited. Quarterly Journal of Music Teaching and Learning 1, no. 2, p. 20-28.

18. Truland, David. 1999. Comprehensive Musicianship in Undergraduate Music Programs. Accessed April 13, 2016:

http://www.auburn.edu/aca demic/classes/ctmu/7970CMP/refs/truland-1997.pdf

19. van Lier, Leo. 2007. Action-based Teaching, Autonomy and Identity. International Journal of Innovation in Language Learning and Teaching 1, no. 1, p. 4665.

20. Ward-Steinman, David e Ward-Steinman, Susan L. 1976. Comparative Anthology of Musical Forms. Vol. 1-2. Belmont: Wadsworth Publishing Company.

21. Wittlich, Gary E. e Humphries, Lee. 1974. Ear Training: An Approach through Music Literature. San Diego: Harcourt College Publishers.

22. Zbikowski, Lawrence e Long, Charles K. 1994. Cooperative Learning in the Music Theory Classroom. Journal of Music Theory Pedagogy 8, p. 135-57.

\footnotetext{
${ }^{1}$ Nota da autora: Este artigo foi inicialmente escrito em inglês para o livro Norton Guide to Teaching Music Theory, ed. Rachel Lumsden and Jeffrey Swinkin. New York: W. W. Norton \& Company, que será publicado em 2018. Meus agradecimentos à Profa. Ilza Nogueira por sua competente tradução para o português do artigo para esta revista.
} 